Int. J. Plant Sci. 163(4):575-579. 2002.

(C) 2002 by The University of Chicago. All rights reserved.

$1058-5893 / 2002 / 16304-0009 \$ 15.00$

\title{
A MANIPULATIVE EXPERIMENT TO ESTIMATE BIPARENTAL INBREEDING IN MONKEYFLOWERS
}

\author{
John K. Kelly ${ }^{1}$ and John H. Willis \\ Department of Ecology and Evolutionary Biology, University of Kansas, Lawrence, Kansas 66045-7534, U.S.A.; and Department of Biology,
} Duke University, Durham, North Carolina 27708-0338, U.S.A.

\begin{abstract}
Biparental inbreeding occurs when plants receive pollen from genetically related neighbors. The frequency of biparental inbreeding in natural populations is unknown but directly relevant to the evolution of plant mating systems. We suggest a simple manipulative experiment to distinguish the effects of biparental inbreeding from those of self-fertilization. The basis of the method is to compare the levels of inbreeding in plants with and without the potential to outcross with genetic relatives. We eliminate the potential for biparental inbreeding by transplanting seedlings to different locations within a population. The level of inbreeding is then estimated from homozygosity at molecular markers. This method is applied in a study of two natural populations of Mimulus guttatus (the yellow monkeyflower) using microsatellites as marker loci. In contrast to previous studies of this species, our study finds no evidence of biparental inbreeding in either population.
\end{abstract}

Keywords: inbreeding, mating systems, Mimulus guttatus, population structure.

\section{Introduction}

Since Darwin (1877a, 1877b, 1877c), evolutionary biologists have taken a great interest in the reproductive strategies of flowering plants. Many plants have elaborate adaptations to avoid self-fertilization and to successfully exchange pollen with other plants. However, outcrossing does not ensure outbred progeny. Natural populations frequently exhibit a distinct spatial structure owing to limited seed dispersal (Bradshaw 1972; Levin 1988). As a consequence, neighboring plants may often be genetic relatives. Since pollinators frequently move among neighboring plants (Pyke 1978; Waser 1986), outcrossed seed may result from matings between genetically related individuals. This process has been termed "biparental inbreeding" to distinguish it from self-fertilization (Uyenoyama 1986).

How frequent is biparental inbreeding in nature? The question is relevant to a number of evolutionary problems, including the prevalence and maintenance of mixed-mating reproductive systems. Mixed-mating plants reproduce by a mixture of outcrossing and self-fertilization. The selfing rate, $s$, is the proportion of seed derived from self-fertilization (many studies actually estimate the outcrossing rate, $t$, where $t=$ $1-s)$. Either $s$ or $t$ can be estimated from progeny arrays, i.e., sets of plants derived from a single mother that have been genotyped at molecular marker loci (Fyfe and Bailey 1951; Brown and Allard 1970; Clegg et al. 1978; Jain 1979; Ritland and Jain 1981). Intermediate estimates of $s(0>s>1)$, which indicate mixed mating, have been obtained from many species (Lloyd 1979; Barrett and Eckert 1990; Vogler and Kalisz 2001).

${ }^{1}$ Author for correspondence; telephone 785-864-3706; e-mail jkk@ku.edu.

Manuscript received November 2001; revised manuscript received March 2002.
The classical mixed-mating model equates outcrossing with random mating. However, if outcrossing involves biparental inbreeding, estimates of the selfing rate will be upwardly biased (Ennos and Clegg 1982; Ritland 1984). Genetic studies of Plantago lanceolata illustrate the potential magnitude of this bias. Applying the mixed-mating model to molecular marker data yields estimates for the selfing rate of up to $16 \%$ (van Dijk et al. 1988; Tonsor et al. 1993). However, as this species is known to be self-incompatible, the elevated homozygosity must be attributable to biparental inbreeding and not selfing. Ellstrand et al. (1978) obtained even higher estimates for the apparent selfing rate in the self-incompatible Helianthus annuus. These examples prompt the question of whether mixedmating systems are as common as widely believed.

The apparent abundance of mixed-mating species is surprising in light of results from evolutionary theory (Lloyd 1979; Lande and Schemske 1985). Simple models predict that mixed-mating systems are evolutionarily unstable. Populations should evolve to either complete outcrossing or complete selfing. However, subsequent theoretical work has identified a number of factors that can favor mixed-mating systems (Uyenoyama et al. 1993; Cheptou and Mathias 2001). One of these factors is biparental inbreeding (Uyenoyama 1986). The direct relevance of biparental inbreeding to both the estimation of mating system parameters and the evolution of these systems provides a compelling justification to estimate the frequency of this process in nature.

In this article, we describe a simple field manipulation to estimate the effects of biparental inbreeding in a population. The basic idea is to compare the levels of inbreeding in plants with and without the potential to outcross with genetic relatives. While a population will exhibit spatial structure (relatedness among neighboring plants) if seed dispersal is limited, biparental inbreeding requires that both seed and pollen dispersal are limited (table 1). We can thus eliminate the potential 
Table 1

Predicted Population Structure under Different Models of Pollen and Seed Dispersal

\begin{tabular}{|c|c|c|c|c|c|}
\hline Model & $\begin{array}{c}\text { Seed } \\
\text { dispersal }\end{array}$ & $\begin{array}{c}\text { Pollen } \\
\text { dispersal }\end{array}$ & $\begin{array}{l}\text { Genetic } \\
\text { relatedness } \\
\text { among } \\
\text { neighbors }\end{array}$ & $\begin{array}{l}\text { Biparental } \\
\text { inbreeding }\end{array}$ & $\begin{array}{l}\text { Homozygosity } \\
\text { among progeny } \\
\text { of natives and } \\
\text { transplants }\end{array}$ \\
\hline 1 & Not limited & Not limited & No & No & Equal \\
\hline 2 & Not limited & Limited & No & No & Equal \\
\hline 3 & Limited & Not limited & Yes & No & Equal \\
\hline 4 & Limited & Limited & Yes & Yes & Higher for natives \\
\hline
\end{tabular}

for biparental inbreeding by transplanting a seedling to a different location within the population. This ensures that a transplant's neighbors will not be genetic relatives, or that they will at least be no more closely related than two random individuals from that population. Any outcrossed progeny of transplanted individuals will be fully outbred with inbreeding coefficient $f=0$. In contrast, a native (untransplanted) individual may have related neighbors, and if pollen dispersal is limited, their outcrossed progeny will have an average $f>0$ (as a result of biparental inbreeding).

Both the spatial genetic structure of a population and the level of inbreeding can be estimated with molecular markers. We use highly polymorphic microsatellite loci to investigate both spatial structure and inbreeding in two populations of Mimulus guttatus $(2 \mathrm{n}=28$; Scrophulariaceae). Commonly known as the yellow monkeyflower, M. guttatus is a self-compatible wild flower that occurs throughout western North America (Vickery 1978). Because M. guttatus self-fertilizes to some extent in the field, we can partition offspring into three different categories: those derived from selfing (a fraction $s$ of the total), those derived from outcrossing between unrelated plants (a fraction $t$ of the total), and those derived from matings between relatives ( $\mathrm{a}$ fraction $r$ of the total). Transplanting eliminates matings between relatives and should reduce the average $f$ of progeny (table 1 ). The predicted difference in offspring homozygosity between transplants and natives depends on both the frequency of biparental inbreeding, as measured by $r$, and the average relatedness of mates, as measured by the coefficient of coancestry (see Lynch and Walsh 1998, p. 135). While the transplant method can estimate the overall contribution of biparental inbreeding, additional information about the spatial distribution of genotypes and the movement of pollinators is necessary to decompose this contribution into its components (see Ritland 2002).

\section{Material and Methods}

The two populations considered in this study, Iron Mountain and Dexter, are annual or winter annual. Iron Mountain is a well-studied site in the Cascade Mountains of Oregon (Willis 1993, 1996). Dexter is a low-elevation site near the town of Dexter in the Willamette Valley (also in Oregon). In June 1997, we initiated two experiments at Iron Mountain. The first investigates the spatial distribution of genotypes within this population. Plants were collected along two parallel transects and genotyped at five microsatellite loci. Along each transect, two plants were collected at each sample point, and sample points were separated by $0.5 \mathrm{~m}$. This design allows estimation of genetic structure at multiple scales. The relatedness of nearest neighbors can be estimated from the genetic similarity of plants derived from the same sample point. Comparisons among pairs at varying distances provide a picture of the larger "neighborhood structure" of the population (e.g., Loiselle et al. 1995). While we give a brief account of the results in "Discussion," a complete description of the methods and results of this spatial genetic analysis is given in Sweigart et al. (1999).

The second experiment, i.e., the transplant experiment, was performed at both Iron Mountain and Dexter. Four parallel transects were established at each site. Each transect was 25 $\mathrm{m}$ long and at least $1 \mathrm{~m}$ distant from other transects within the site. Fifty seedlings were tagged along each transect (they were uniformly distributed at $0.5-\mathrm{m}$ intervals) and numbered sequentially. Plants with even identification numbers (2, 4, $6, \ldots, 200)$ were randomly transplanted to another even-numbered position within the array. Odd-numbered plants were dug out of the ground and then placed back into the same position to control for the effects of removal. Plants were periodically monitored through maturation and flowering. Fruits were collected from all plants that survived and flowered. We also attempted to preserve and collect tissue from the maternal plants, although many died when removed from the field.

Seeds from these fruits were subsequently planted in the greenhouse, and five plants per family were grown to flower. Corolla tissue was collected from these plants and stored for DNA extraction. Because of germination failure or failure to flower, the number of plants successfully genotyped was fewer than five for many of the families. We used the general PCR reaction conditions and thermocycle programs described in Kelly and Willis (1998) for genotyping, except that the $5^{\prime}$ primers were end labeled with infrared (IRD) dyes for visualization with a Li-Cor automated sequencing system. A detailed description of the procedures is given in Fishman et al. (2001). Briefly, the PCR products were resolved on $18 \mathrm{~cm}$ of denaturing polyacrylamide gels run on a Li-Cor $4000 \mathrm{~L}$ automated sequencer according to the gel preparation and loading protocols of Remington et al. (1998). Before gel loading, $5 \mu \mathrm{L}$ of formamide loading dye was added to each reaction. The samples were denatured by heating to $75^{\circ}-85^{\circ} \mathrm{C}$ for $2 \mathrm{~min}$ and then immediately chilled to $4^{\circ} \mathrm{C}$. We loaded $1-2 \mu \mathrm{L}$ of dye/product mixture into each sample lane (48-well comb) and also ran parental genotypes and/or IRD-labeled size standards in the outermost lanes. We used electrophoretic run parameters of $1000 \mathrm{~V}, 35 \mathrm{~mA}, 25 \mathrm{~W}, 50^{\circ} \mathrm{C}$ plate temperature, scan speed 3 , 
signal filter 3, and 16-bit pixel depth for the collection of TIFF image files. We scored fragments by eye in the TIFF image files using the program RFLPSCAN 3.0 (1998; Scanalytics, Fairfax, Va.). The segregating fragments were assigned molecular weights by the program according to the molecular weight standards and the previously determined parental allele sizes.

The progeny from Iron Mountain were scored at five loci: AG 19, AAT 9, AAT 211, AAT 300, and AAT 356. The progeny from Dexter were scored at four loci, which included all of the above except AAT 9. These loci were known to be highly polymorphic. The data from the spatial genetic study yielded estimates for gene diversity (Weir 1996, p. 151) at these loci of $0.93,0.79,0.83,0.81$, and 0.89 , respectively (Sweigart et al. 1999). These numbers represent the expected frequency of heterozygotes at a locus for a population with the same allele frequencies but no inbreeding (in Hardy-Weinberg equilibrium).

\section{Results}

At Iron Mountain, 34 transplants and 30 natives produced sufficient seed to genotype progeny (a total of 118 progeny from transplants and 143 from natives). Not all progeny were successfully genotyped for all five markers. At Dexter, we obtained seed from 25 transplants and 27 natives (a total of 95 progeny from each type of parent). The results are displayed in table 2. The number of distinct alleles that were identified in the sample (natives and transplants combined) is given for each marker locus.

A simple test for biparental inbreeding is to compare levels of heterozygosity among transplanted and native families. As each type of family is derived from parents uniformly distributed over each population, there should be no difference in allele frequencies between classes. Thus, under the null hypothesis of no biparental inbreeding, we expect the frequency of heterozygotes at each locus to be the same within transplanted and native families. For each family, we determined the fraction of individuals that were heterozygotes at each locus. The average values of these proportions (across families) for each locus are given in the last two columns of table 2 . There are no significant differences between transplanted and native families at any locus in either population.

Averaging within families was used because a preliminary inspection revealed that individuals within a family are not statistically independent with regard to their determination as outcrossed or selfed. There is a positive correlation of selfing among siblings in the terminology of Ritland (1989). Averaging is thus required because each offspring does not provide independent information about the underlying probabilities of selfing or biparental inbreeding. The negative results in table 2 also prompt a comment on statistical power. Power is a concern because there are substantial quantitative differences in average heterozygosity at some markers. In principle, greater power could be achieved by using a statistic that integrates over loci. However, as most of the differences in table 2 are in the wrong direction (with lower heterozygosity in progeny of transplants), it seems unlikely that such an analysis would change our conclusions. As discussed in greater detail below, a more complete analysis is possible when both maternal and offspring genotypes are known.
Table 2

Number of Alleles and Observed Heterozygosities (with SE) at Iron Mountain and Dexter

\begin{tabular}{lccc}
\hline Locus & $\begin{array}{c}\text { Number of } \\
\text { alleles }\end{array}$ & $\begin{array}{c}\text { Average } \mathrm{H} \\
\text { transplant }\end{array}$ & $\begin{array}{c}\text { Average H } \\
\text { native }\end{array}$ \\
\hline $\begin{array}{l}\text { Iron Mountain: } \\
\text { 1. AG 19 }\end{array}$ & 25 & $0.65(0.06)$ & $0.79(0.05)$ \\
2. AAT 9 & 26 & $0.49(0.06)$ & $0.54(0.07)$ \\
3. AAT 211 & 13 & $0.54(0.06)$ & $0.49(0.06)$ \\
4. AAT 300 & 20 & $0.37(0.06)$ & $0.51(0.07)$ \\
5. AAT 356 & 29 & $0.55(0.07)$ & $0.68(0.05)$ \\
Dexter: & & & \\
1. AG 19 & 28 & $0.77(0.07)$ & $0.66(0.07)$ \\
2. AAT 211 & 11 & $0.64(0.06)$ & $0.57(0.08)$ \\
3. AAT 300 & 27 & $0.40(0.08)$ & $0.47(0.08)$ \\
4. AAT 356 & 22 & $0.58(0.06)$ & $0.58(0.08)$ \\
\hline
\end{tabular}

\section{Discussion}

We find no evidence of biparental inbreeding in two populations of Mimulus guttatus. This result is surprising given that bumblebees (Bombus sp.) are an important pollinator of M. guttatus (Robertson et al. 1999; MacNair and Gardner 1998) and that these animals routinely move among neighboring plants when foraging (Pyke 1978). However, biparental inbreeding requires not only localized mating but also genetic relatedness among neighboring plants (table 1). The spatial genetic study of Iron Mountain reveals that the genetic relatedness of neighboring plants is near zero (Sweigart et al. 1999). While we do not have comparable spatial genetic data for Dexter, the results in table 2 indicate that the inbreeding that does occur in this population must be due to self-fertilization. Thus, both Iron Mountain and Dexter can be safely classified as genuine mixed-mating populations.

The most widely used test for biparental inbreeding employs a comparison between single and multilocus statistics (Ritland and Jain 1981; Shaw et al. 1981; Ritland 1990). Biparental inbreeding will reduce $t_{\mathrm{s}}$, the average single locus estimate for the outcrossing rate, relative to $t_{\mathrm{m}}$, the multilocus estimate. Ritland (2002) has recently generalized his estimation programs for $t_{\mathrm{s}}$ and $t_{\mathrm{m}}$ (now titled MLTR) to accommodate microsatellite loci. We applied MLTR to our data and found that natives and transplants yield indistinguishable estimates for $t_{\mathrm{s}}$ and $t_{\mathrm{m}}$ at both Iron Mountain and Dexter (results not shown). Because biparental inbreeding should reduce $t_{\mathrm{s}}$ relative to $t_{\mathrm{m}}$ in natives but not transplants, this analysis is fully consistent with the heterozygosity analysis in table 2 .

The agreement of results from the spatial genetic and transplant experiments at Iron Mountain is reassuring. The transplant method indicates the absence of biparental inbreeding where it should not be occurring. Will the transplant method correctly identify biparental inbreeding in populations in which it does occur? C. Muis and C. Eckert (unpublished manuscript) have recently compared direct (transplant) and indirect $\left(t_{\mathrm{s}}\right.$ vs. $\left.t_{\mathrm{m}}\right)$ methods to estimate biparental inbreeding in Aquilegia canadensis. Using genetic data from two allozyme loci, they document significant spatial genetic structure in three of four populations of this species. There is thus substantial opportunity for biparental inbreeding. However, estimates of the 
difference between $t_{\mathrm{s}}$ and $t_{\mathrm{m}}$ suggest that biparental inbreeding is infrequent. Because the indirect method is known to underestimate the incidence of biparental inbreeding (Brown 1990), Muis and Eckert (2002) performed a transplant experiment in two of their populations. Higher homozygosity in the progeny of natives indicates that almost $20 \%$ of outcross matings are between relatives. Thus, the indirect method underestimates the actual frequency of biparental inbreeding by more than tenfold. These results provide strong support for the transplant method.

In contrast to this study, Ritland and Ganders (1987) did find evidence for biparental inbreeding in populations of $M$. guttatus from Washington State and British Columbia (see also Leclerc-Potvin and Ritland 1994). They used a different estimation method that relies on information about the spatial distribution of genotypes. In contrast to Iron Mountain, each of the Ritland and Ganders (1987) populations exhibit significant spatial structure. These differences are not surprising given that M. guttatus is really a species complex composed of many populations with varying reproductive biologies (Grant 1924; Vickery 1978). Previous studies have demonstrated interpopulation differences in floral morphology (Waser et al. 1982), amount of genetic variation for floral traits (Carr and Fenster 1994; Robertson et al. 1994), selfing rate (Ritland and Ganders 1987; Willis 1993; Awadalla and Ritland 1997), and timing of selfing over the life span of the flower (Dole 1990, 1992; Dudash and Ritland 1991; Leclerc-Potvin and Ritland 1994; Arathi et al. 2002). We can now add the incidence of biparental inbreeding to this list.

While the diversity of reproductive attributes among M. guttatus populations certainly merits detailed consideration, the main purpose of this article is to introduce the transplant method for estimating biparental inbreeding. In this application of the method, we used variation at highly polymorphic microsatellite loci. These loci provide excellent materials to estimate mating system parameters. Because each locus has a large number of relatively infrequent alleles, an outbred individual will be heterozygous at most microsatellite loci. For the loci considered in this study, the probability of heterozy- gosity ranges from 0.79 to 0.93 per locus (Sweigert et al. 1999). Multilocus homozygosity is thus a compelling indicator of inbreeding. With highly polymorphic loci, homozygosity is strongly linked to identity by descent. Inferring the latter from the former is an essential feature of mating system estimation.

In this study, we were unable to determine the genotypes for most of the maternal parents. Future applications of the transplant method should endeavor to obtain these data because they allow several important refinements of the analysis. First, since the maternal parents are sampled from known positions within the population, these data are directly informative about the spatial genetic structure of the population (Heywood 1991). Second, knowledge of the maternal genotype greatly facilitates analysis of the progeny. For the families in this study for which we were able to determine maternal genotype, outcrossed progeny can easily be distinguished from self-fertilized progeny by simple inspection of their genotypes. Selfed offspring only have alleles that are present in the mother, whereas outcrossed progeny are very likely to have a foreign allele at one or more loci. When it is possible to subdivide progeny in this way, biparental inbreeding can be measured as increased homozygosity within outcrossed progeny. This greatly increases statistical power and should allow transplant experiments to detect even low levels of biparental inbreeding.

\section{Acknowledgments}

We would like to thank S. Tonsor, B. Obbo, H. S. Arathi, S. Williamson, A. Stephenson, and two anonymous reviewers for comments on the manuscript. Celine Muis and Chris Eckert graciously provided a copy of their unpublished manuscript. Kermit Ritland provided important advice concerning the application of his estimation programs. Aimee Decker and L. Biado assisted with the field and greenhouse work, while Andrea Sweigart performed much of the laboratory microsatellite work. This work was supported by grants from the National Science Foundation (DEB-9903758 to J. Kelly and DEB972758 and DEB-0075704 to J. Willis).

\section{Literature Cited}

Arathi HS, A Rasch, C Cox, JK Kelly 2002 Autogamy and floral longevity in Mimulus guttatus. Int J Plant Sci 163:567-573.

Awadalla P, K Ritland 1997 Microsatellite variation and evolution in the Mimulus guttatus species complex with contrasting mating systems. Mol Biol Evol 14:1023-1034.

Barrett SCH, CG Eckert 1990 Variation and evolution of mating systems in seed plants. Pages 229-254 in S Kawano, ed. Biological approaches and evolutionary trends in plants. Academic Press, Tokyo.

Bradshaw AD 1972 Some evolutionary consequences of being a plant. Evol Biol 5:25-47.

Brown AHD 1990 Genetic characterization of plant mating systems. Pages 145-162 in AHD Brown, MT Clegg, A Kahler, B Weir, eds. Plant population genetics, breeding and genetic resources. Sinauer, Sunderland, Mass.

Brown AHD, RW Allard 1970 Estimation of the mating system in open-pollinated maize populations using isozyme polymorphisms. Genetics 66:133-145.
Carr DE, CB Fenster 1994 Levels of genetic variation and covariation for Mimulus (Scrophulariaceae) floral traits. Heredity 72:606-618.

Cheptou PO, A Mathias 2001 Can varying inbreeding depression select for intermediary selfing rates? Am Nat 157:361-373.

Clegg MT, AL Kahler, RW Allard 1978 Estimation of life cycle components of selection in an experimental plant population. Genetics 89:765-792.

Darwin CR $1877 a$ The different forms of flowers on plants of the same species. J Murray, London.

$1877 b$ The effects of cross and self fertilisation in the vegetable kingdom. Appleton, New York.

$1877 c$ The various contrivances by which orchids are fertilised by insects. J Murray, London.

Dole JA 1990 Role of corolla abscission in delayed self-pollination of Mimulus guttatus (Scrophulariaceae). Am J Bot 77:1505-1507.

1992 Reproductive assurance mechanisms in three taxa of the Mimulus guttatus complex (Scrophulariaceae). Am J Bot 79:650-659.

Dudash MR, K Ritland 1991 Multiple paternity and self-fertilization in relation to floral age in Mimulus guttatus. Am J Bot 78:1746-1753. 
Ellstrand NC, AM Torres, DA Levin 1978 Density and the rate of apparent outcrossing in Helianthus annuus (Asteraceae). Syst Bot 3:403-407.

Ennos RA, MT Clegg 1982 Effect of population substructuring on estimates of outcrossing rate in plant populations. Heredity 48: 283-292.

Fishman L, AJ Kelly, E Morgan, JH Willis 2001 A genetic map in the Mimulus guttatus species complex reveals transmission ratio distortion due to heterospecific interactions. Genetics 159:1701-1716.

Fyfe JL, NTJ Bailey 1951 Plant breeding studies in leguminous forage crops. I. Natural crossbreeding in winter beans. J Agr Sci 41:371-378.

Grant AL 1924 A monograph of the genus Mimulus. Ann Mo Bot Gard 11:99-398.

Heywood JS 1991 Spatial analysis of genetic variation in plant populations. Annu Rev Ecol Syst 22:335-355.

Jain SK 1979 Estimating outcrossing rate: some alternative procedures. Crop Sci 19:23-26.

Kelly AJ, JH Willis 1998 Polymorphic microsatellite loci in Mimulus guttatus and related species. Mol Ecol 7:769-774.

Lande R, DW Schemske 1985 The evolution of self-fertilization and inbreeding depression in plants. I. Genetic models. Evolution 39: 24-40.

Leclerc-Potvin C, K Ritland 1994 Modes of self-fertilization in Mimulus guttatus (Scrophulariaceae): a field experiment. Am J Bot 81: 199-205.

Levin DA 1988 Local differentiation and the breeding structure of plant populations. Pages 305-329 in LD Gottleib, SK Jain, eds. Plant evolutionary biology. Chapman \& Hall, New York.

Lloyd DG 1979 Some reproductive factors affecting the selection of self-fertilization in plants. Am Nat 113:67-79.

Loiselle BA, VL Sork, J Nason, C Graham 1995 Spatial genetic structure of a tropical understory shrub, Psychotria officinalis (Rubiaceae). Am J Bot 82:1420-1425.

Lynch M, B Walsh 1998 Genetics and analysis of quantitative characters. Sinauer, Sunderland, Mass.

MacNair MR, M Gardner 1998 The evolution of edaphic ecotypes. Pages 157-171 in DJ Howard, SH Berlocher, eds. Endless forms: species and speciation. Oxford University Press, New York.

Pyke GH 1978 Optimal foraging: movement patterns of bumblebees between inflorescences. Theor Popul Biol 13:72-98.

Remington DL, RW Whetten, BH Liu, DM O’Malley 1998 Construction of an AFLP genetic map with nearly complete genome coverage in Pinus taeda. Theor Appl Genet 98:1279-1292.

Ritland K 1984 The effective proportion of self-fertilization with consanguineous matings in inbred populations. Genetics 106:139-152.

1989 Correlated matings in the partial selfer Mimulus guttatus. Evolution 43:848-859.
1990 A series of FORTRAN computer programs for estimating plant mating systems. J Hered 81:235-237.

2002 Extensions of models for the estimation of mating systems using $n$ independent loci. Heredity 88:221-228.

Ritland K, FR Ganders 1987 Covariation of selfing rates with parental gene fixation indices within populations of Mimulus guttatus. Evolution 41:760-771.

Ritland K, S Jain 1981 A model for the estimation of outcrossing rate and gene frequencies using $n$ independent loci. Heredity 47:35-52.

Robertson AW, A Diaz, MR MacNair 1994 The quantitative genetics of floral characters in Mimulus guttatus. Heredity 72:300-311.

Robertson AW, C Mountjoy, BE Faulkner, MV Roberts, MR Macnair 1999 Bumble bee selection of Mimulus guttatus flowers: the effects of pollen quality and reward depletion. Ecology 80:2594-2606.

Shaw DV, AL Kahler, RW Allard 1981 A multilocus estimator of mating system parameters in plant populations. Proc Natl Acad Sci USA 78:1298-1302.

Sweigart A, K Karoly, A Jones, JH Willis 1999 The distribution of individual inbreeding coefficients and pairwise relatedness in a population of Mimulus guttatus. Heredity 83:625-632.

Tonsor SJ, S Kalisz, J Fisher, TP Holtsford 1993 A life-history based study of population genetic structure: seed bank to adults in Plantago lanceolata. Evolution 47:833-843.

Uyenoyama MK 1986 Inbreeding and the cost of meiosis: the evolution of selfing in populations practicing biparental inbreeding. Evolution 40:388-404.

Uyenoyama MK, KE Holsinger, DM Waller 1993 Ecological and genetic factors directing the evolution of self-fertilization. Oxf Surv Evol Biol 9:327-381.

Van Dijk H, K Wolff, A De Vries 1988 Genetic variability in Plantago species in relation to their ecology. 3. Genetic structure of populations of P. major, P. lanceolata, and P. coronopus. Theor Appl Genet 75:518-528.

Vickery RK 1978 Case studies in the evolution of species complexes in Mimulus. Evol Biol 11:405-507.

Vogler DW, S Kalisz 2001 Sex among the flowers: the distribution of plant mating systems. Evolution 55:202-204.

Waser NM 1986 Flower constancy: definition, cause, and measurement. Am Nat 127:593-603.

Waser NM, RK Vickery, MV Price 1982 Patterns of seed dispersal and population differentiation in Mimulus guttatus. Evolution 36: 753-761.

Weir BS 1996 Genetic data analysis II: methods for discrete population genetic data. Sinauer, Sunderland, Mass.

Willis JH 1993 Partial self-fertilization and inbreeding depression in two populations of Mimulus guttatus. Heredity 71:145-154.

1996 Measures of phenotypic selection are biased by partial inbreeding. Evolution 50:1501-1511. 